\title{
Hydrolysis as a basis for processing vegetable waste into bioplastics
}

\author{
Guzel Ilalova ${ }^{1}$, Ruslan Safin ${ }^{1}$, Shamil Mukhametzyanov ${ }^{1 *}$ and Albina Gazizullina ${ }^{2}$ \\ ${ }^{1}$ Kazan National Research Technological University, Kazan, Russia \\ ${ }^{2}$ National Technology Initiative Center for Advanced Manufacturing Technologies based on the \\ Institute of Advanced Manufacturing Technologies of Peter the Great St. Petersburg Polytechnic \\ University Polytechnicheskaya, 29, St. Petersburg, 195251, Russia
}

\begin{abstract}
The greening of processing waste from logging and woodworking industries involves measures to prevent the negative impact of production processes on the natural environment and is enabled by the development of resource-saving techniques that minimize harmful emissions to the environment. These production operations are based on hydrolytic cleavage of glycoside bonds of vegetable biomass polysaccharides with the formation of monosaccharides as the main reaction products.

Despite the wide range of available methods of processing wood into promising materials (heat treatment, pyrolysis, hydrolysis, etc.), one of the most effective methods is to produce sugars by weak acids hydrolysis.

In this regard, the paper describes the technology of high-temperature hydrolysis of pine sawdust with sulfurous acid in order to detect reducing substances (RS) in the hydrolysis residue. The paper considers the effect of sulfurous acid, temperature, and treatment time on the yield of RS.
\end{abstract}

\section{Introduction}

Today in Russia, a large amount of waste is generated in logging and woodworking industries. Part of it is burned, and part is taken to landfills. However, these types of waste disposal have a negative impact on the environment. The concern of many authors about wood waste disposal has led to the growth of significance of research on effective ways to process and use wood waste [1-5].

Woodwaste is the main resource of lignocellulosic materials, which, in addition, are renewable. Recycling of wood waste is an important part of the wood processing industry as the benefits of wood can be not only before its processing, but also after it. Due to the high content of organic substances in wood biomass, namely cellulose, lignin and hemicellulose, which are part of cell walls, it is useful and can be further processed, for example, it can be used either as a raw material for hydrolysis or for the production of cardboard, fiberboard and other valuable materials [6-9].

Despite the wide range of available methods of processing wood into promising materials (heat treatment, pyrolysis, hydrolysis, etc.) [10-12], one of the most effective

*Corresponding author:joker775.87@mail.ru 
methods is to produce sugars by weak acids hydrolysis. Hydrolysis is interaction of substances with water. Different classes of inorganic and organic substances are hydrolyzed [10]. Hydrolysis can be carried out at high or low temperatures, using various acids (hydrochloric, phosphoric, sulfuric).

The use of acids for vegetable raw materials hydrolysis has been known for a long time. In many studies, sulfuric acid was used as a hydrolyzing agent. The work [2] presents studies on high-temperature hydrolysis of straw with sulfuric acid. Varying the temperature and concentration of sulfuric acid helped determine that at sulfuric acid concentration of $1 \%$ and a temperature change in the range of $150-190^{\circ} \mathrm{C}$, the maximum concentration of reducing substances was reached, respectively, 50-40 minutes after the start of hydrolysis, and at sulfuric acid concentration of 3\% in 20-10 minutes, respectively. In addition, the authors have studied the formation of by-products depending on pressure and concluded that a large increase in pressure leads to a deterioration of the biological quality of the hydrolysate. In addition, an increase in the temperature and in acid concentration resulted in a $\mathrm{pH}$ increase, which indicates acid consumption during hydrolysis. As a result, the authors concluded that the preferred mode of hydrolysis of straw with sulfuric acid at $180^{\circ} \mathrm{C}$ and an acid concentration of at least $2 \%$.

Biomass hydrolysis was also performed in the Renewable Energy Laboratory at Guangzhou Institute of Energy Conversion, China. Scientists W. Qi, X. Zhuang, Y. et al. [3] found that when sulfuric acid is used for biomass hydrolysis, in addition to macrofactors (reaction temperature, acid concentration, reaction time, and solid-to-liquid ratio), the rate of acid diffusion into the biomass particle is also an important factor affecting hydrolysis. They used pine sawdust as the test material and proposed a kinetic model for distribution of sulfuric acid by studying the diffusion characteristics in a heterogeneous phase consisting of sawdust and acid solution. Comparison of the calculated results using the model with the experimental results showed that the kinetic model allows us to predict satisfactorily the process of sulfuric acid diffusion into the sawdust particle during the reaction. Based on the distribution model, the researchers studied the effect of particle microstructure on the concentration distribution of sulfuric acid.

A significant number of studies in Russia are devoted to the hydrolysis of agricultural raw materials: wheat straw, maize cobs, beet pulp, etc.. Pretreatment and enzymatic hydrolysis of beet pulp and wheat straw is the subject of the work [1], which describes the complete hydrolysis process. The conducted research allowed the author to conclude that pretreatment of beet pulp at sulfurous acid concentration of $1 \%$, at a temperature of $190^{\circ} \mathrm{C}$, for 10 minutes and pretreatment of wheat straw at a temperature of $200^{\circ} \mathrm{C}$, at an acid concentration of $1.18 \mathrm{wt}$. for 15 minutes allowed an increase of glucose yield during enzymatic hydrolysis by 4.6 and 2.4 times, respectively. The author also studied the monosaccharide composition of hydrolysates.

However, the raw materials of the hydrolysis industry can also be sawmill and woodworking waste, as well as low-quality wood [3-12]. A large number of Russian and foreign researchers have worked on wood biomass hydrolysis. Thus, scientists at the Forest Products Laboratory at Mississippi State University investigated the fast steam hydrolysis of wood chips and found that lignin isolated from solid residue was particularly reactive, and lignin collected in steam condensate was also very reactive, apparently due to its rapid cooling after removal from the reactor [12].

Currently, the use of sulfurous acid as a hydrolyzing agent is promising, since sulfurous acid reduces the consumption of the hydrolyzing agent due to its recovery. In addition, the undoubted advantage of using sulfurous acid is its low corrosion activity and ease of subsequent purification of the resulting sugars from the acid.

The purpose of this study conducted in the Laboratory of Engineering Problems of biotechnology of KNRTU, is to acquire accurate data on the effect of temperature and acid 
concentration on the yield of reducing substances for further processing into polyhydroxyalkanoates.

\section{Methods and Materials}

Due to its good properties in terms of hydrolysis, pine is the most suitable type of wood. Therefore, for hydrolysis, sawdust of Scots pine (Pinus Sylvestris) with a fraction of up to $2 \mathrm{~mm}$ and laboratory sulfurous acid were used as raw materials.

An important parameter in hydrolysis is the hydromodulus (the ratio of the vegetable raw material weight to the weight or volume of an aqueous acid solution) [7]. Depending on the hydromodulus value, the yield of sugar from the raw material, its concentration in the hydrolysate, and the acid consumption significantly change. The hydromodulus of 1:5.8 was selected experimentally.

Acid hydrolysis was carried out on a hydrolyzer with a heat accumulator, consisting of six sealed stainless $30 \mathrm{ml}$ capsules (Fig. 1). Sawdust previously weighed on analytical scales, was placed in capsules using a funnel with a subsequent addition of calculated amounts of distilled water and sulfurous acid under a draught. Further, the capsules containing the study object were simultaneously placed in a hydrolyzer preheated to the test temperature.

Hydrolysis was studied for one-and two-stage periodic processes.

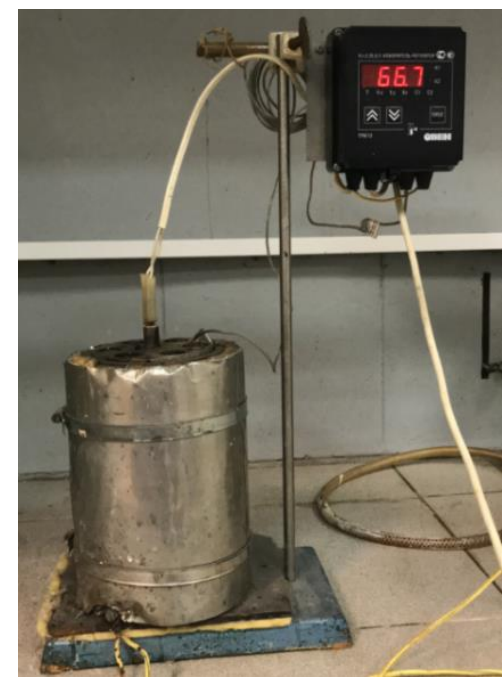

Fig. 1. Capsule type hydrolyser with a metal heat accumulator.

Single-stage hydrolysis was carried out as follows: the capsules were sequentially removed from the hydrolyzing unit at a certain time interval $(20,40,60,80,100,120$ minutes for a temperature of $160^{\circ} \mathrm{C}$ and $10,20,30,40,60,90$ minutes for a temperature of $170^{\circ} \mathrm{C}$ ) using a special gripper and cooled with running water. After the hydrolysis, the contents of the capsules were separated by straining into the liquid and dry residue to further determine the content of reducing substances.

The study of the two-stage periodic sawdust hydrolysis was carried out as follows: after analyzing the results of the single-stage process we determined the rational duration of the first stage of the two-stage hydrolysis. Then an experiment was conducted, where the first stage preparatory procedures and experiments were similar to the single-stage process and differed only in duration. After the end of the first stage, the solid residue was separated from the hydrolysate, dried, and sent for experimental studies of the second stage. The 
conditions for the second stage were similar to the first stage, but the time interval between measurements was reduced to 5 minutes.

The amount of reducing substances was determined using the Macaigne-Schoorl method, which consists in using a Fehling solution with a given copper content and iodometric determination of the amount of copper (II) unspent during the reaction. The separated dry residue was placed on an ANDMS-70 thermal gravimetric humidity analyzer to determine the dry matter content in the hydrolysis mixture (Fig. 2).

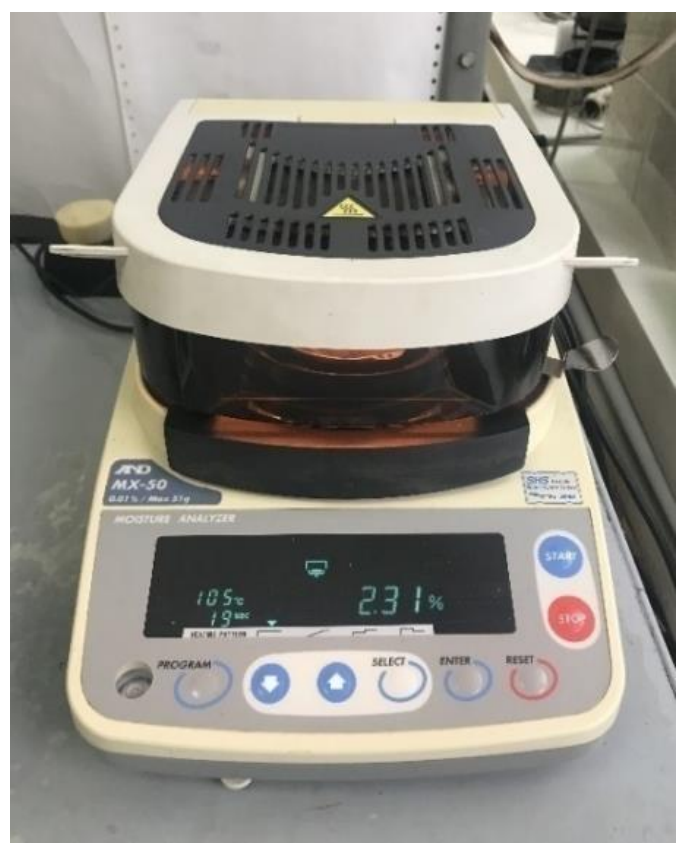

Fig. 2. ANDMS-70 thermal gravimetric humidity analyser.

\section{Results and Discussion}

We conducted experiments on pine sawdust hydrolysis in the temperature range of 160 $180^{\circ} \mathrm{C}$ and sulfuric acid concentration of $4 \%$ by weight, over a different time range.

The study of pine sawdust hydrolysis kinetics at a temperature of $160^{\circ} \mathrm{C}$, time range of $20-120$ minutes (every 20 minutes the capsules were removed), and the concentration of sulfurous acid of $4 \%$ by weight showed that the highest yield of reducing substances in the hydrolysis solution occurred at the 30th minute, then was a recession, but at the 80th minute the RS output again began to grow (Fig. 3). This means that between the 30th and the 80th min less stable substances, i.e. monosaccharides, decomposed.

An increase in the temperature to $170^{\circ} \mathrm{C}$, maintaining the sulfurous acid concentration at $4 \%$ by weight and a time range of $10-90$ minutes, provided a significant change in the results of the experiments. Figure 3 shows that the highest RS concentration is reached at 20 minutes, then the graph goes down. At the 60th minute, like in the previous experiment, the second stage of wood decomposition is observed.

Further temperature increase to $180^{\circ} \mathrm{C}$ led to the highest RS concentration at the 10 th minute in the time range of 10-90 minutes, and at the 30th minute, the second stage of decomposition occurred. 


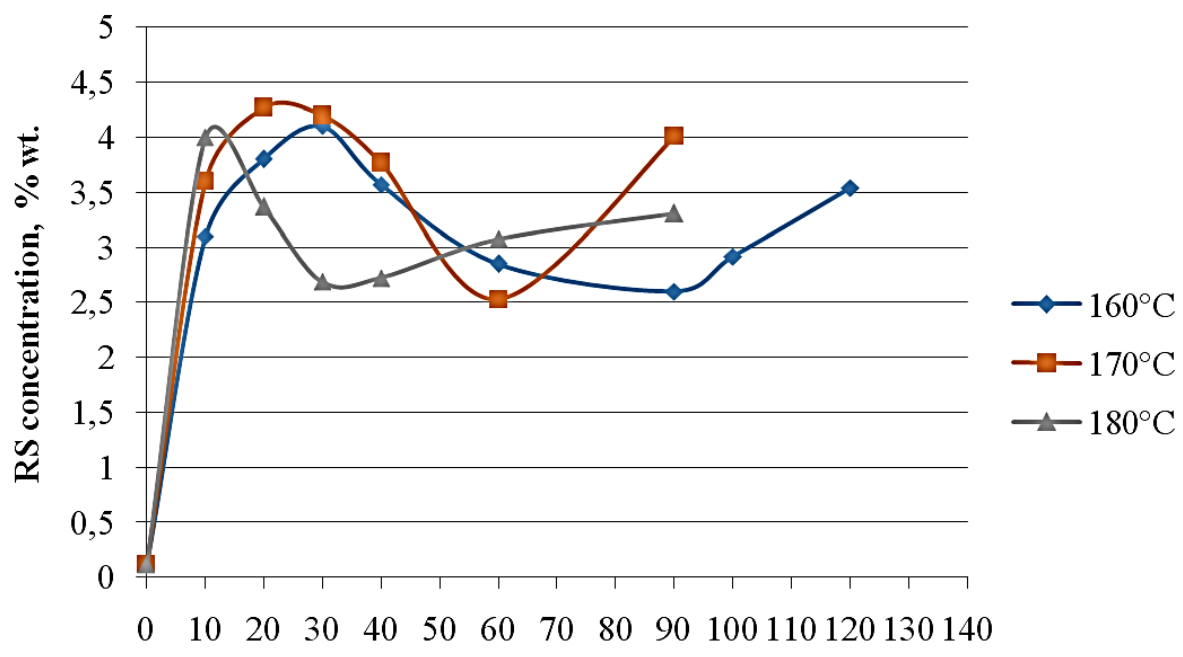

Hydrolysis time, min

Fig. 3. Changes in reducing substances concentration during hydrolysis at $160^{\circ} \mathrm{C}, 170^{\circ} \mathrm{C}$ and $180^{\circ} \mathrm{C}$, sulfurous acid concentration $4 \%$.

Calculated pine sawdust hydrolysis data resulting from titrimetric analysis (titration), are presented in Tables 1, 2 and 3.

Table 1. Reducing substances concentration $(\%)$ at $160^{\circ} \mathrm{C}$.

\begin{tabular}{|c|c|c|c|c|c|c|c|}
\hline Time & Control & I & II & III & IV & $\begin{array}{c}\text { sugar, } \\
\text { mg }\end{array}$ & sugar, \% \\
\hline $\mathbf{0}$ & 26.00 & 25.60 & 0.40 & 6.0705 & 2.4282 & 1.1905 & 0.1190 \\
\hline $\mathbf{2 0}$ & 26.00 & 12.90 & 13.10 & 6.0705 & 79.5236 & 41.0505 & $\mathbf{4 . 1 0 5 1}$ \\
\hline $\mathbf{4 0}$ & 26.00 & 14.50 & 11.50 & 6.0705 & 69.8108 & 35.6972 & 3.5697 \\
\hline $\mathbf{6 0}$ & 26.00 & 16.70 & 9.30 & 6.0705 & 56.4557 & 28.4900 & 2.8490 \\
\hline $\mathbf{8 0}$ & 26.00 & 18.00 & 8.00 & 6.0705 & 48.5640 & 24.3130 & 2.4313 \\
\hline $\mathbf{1 0 0}$ & 26.00 & 16.50 & 9.50 & 6.0705 & 57.6698 & 29.1380 & 2.9138 \\
\hline
\end{tabular}

Table 2. Reducing substances concentration $(\%)$ at $170^{\circ} \mathrm{C}$.

\begin{tabular}{|c|c|c|c|c|c|c|c|}
\hline Time & Control & I & II & III & IV & $\begin{array}{c}\text { sugar, } \\
\text { mg }\end{array}$ & sugar, \% \\
\hline $\mathbf{0}$ & 26.00 & 25.60 & 0.40 & 6.0705 & 2.4282 & 1.1905 & 0.1190 \\
\hline $\mathbf{1 0}$ & 26.00 & 13.80 & 12.20 & 6.0705 & 74.0601 & 38.0274 & 3.8027 \\
\hline $\mathbf{2 0}$ & 26.00 & 13.00 & 13.00 & 6.0705 & 78.9165 & 40.7131 & 4.0713 \\
\hline $\mathbf{3 0}$ & 26.00 & 12.30 & 13.70 & 6.0705 & 83.1659 & 43.0830 & $\mathbf{4 . 3 0 8 3}$ \\
\hline $\mathbf{4 0}$ & 26.00 & 13.90 & 12.10 & 6.0705 & 73.4531 & 37.6934 & 3.7693 \\
\hline $\mathbf{6 0}$ & 26.00 & 17.70 & 8.30 & 6.0705 & 50.3852 & 25.2716 & 2.5272 \\
\hline $\mathbf{9 0}$ & 26.00 & 15.00 & 11.00 & 7.0705 & 77.7755 & 40.0799 & 4.0080 \\
\hline
\end{tabular}


Table 3. Reducing substances concentration $(\%)$ at $180^{\circ} \mathrm{C}$.

\begin{tabular}{|c|c|c|c|c|c|c|c|}
\hline Time & Control & I & II & III & IV & $\begin{array}{c}\text { sugar, } \\
\text { mg }\end{array}$ & sugar, \% \\
\hline $\mathbf{0}$ & 26.00 & 25.60 & 0.40 & 6.0705 & 2.4282 & 1.1905 & 0.1190 \\
\hline $\mathbf{1 0}$ & 26.00 & 13.20 & 12.80 & 6.0705 & 77.7024 & 40.0394 & $\mathbf{4 . 0 0 3 9}$ \\
\hline $\mathbf{2 0}$ & 26.00 & 15.10 & 10.90 & 6.0705 & 66.1685 & 33.71342 & 3.3714 \\
\hline $\mathbf{3 0}$ & 26.00 & 17.20 & 8.80 & 6.0705 & 53.4204 & 26.8763 & 2.6876 \\
\hline $\mathbf{4 0}$ & 26.00 & 17.10 & 8.90 & 6.0705 & 54.0275 & 27.1984 & 2.7198 \\
\hline $\mathbf{6 0}$ & 26.00 & 16.00 & 10.00 & 6.0705 & 60.7050 & 30.7642 & 3.0764 \\
\hline $\mathbf{9 0}$ & 26.00 & 16.80 & 9.20 & 7.0705 & 65.0486 & 33.1071 & 3.3107 \\
\hline
\end{tabular}

Based on Tables 1-3, the highest RS concentration in the liquid residue was determined at temperatures of $160^{\circ} \mathrm{C}, 170^{\circ} \mathrm{C}, 180^{\circ} \mathrm{C}$. Hence, two-stage hydrolysis was studied with the dry residue obtained at the 10th, 20th and 30th minutes, respectively. The two-stage hydrolysis enabled us to plot the graphs shown in Figures 4-6. Figure 4 shows the first stage of hydrolysis. It can be seen that at $180^{\circ} \mathrm{C}$, the process of RS formation begins much faster than at $160^{\circ} \mathrm{C}$ and $170^{\circ} \mathrm{C}$. However, the RS concentration decreases at $180^{\circ} \mathrm{C}$, which is due to the increased temperature and premature decomposition of reducing substances.

Place the figure as close as possible after the point where it is first referenced in the text. If there is a large number of figures and tables, it might be necessary to place some before their text citation.

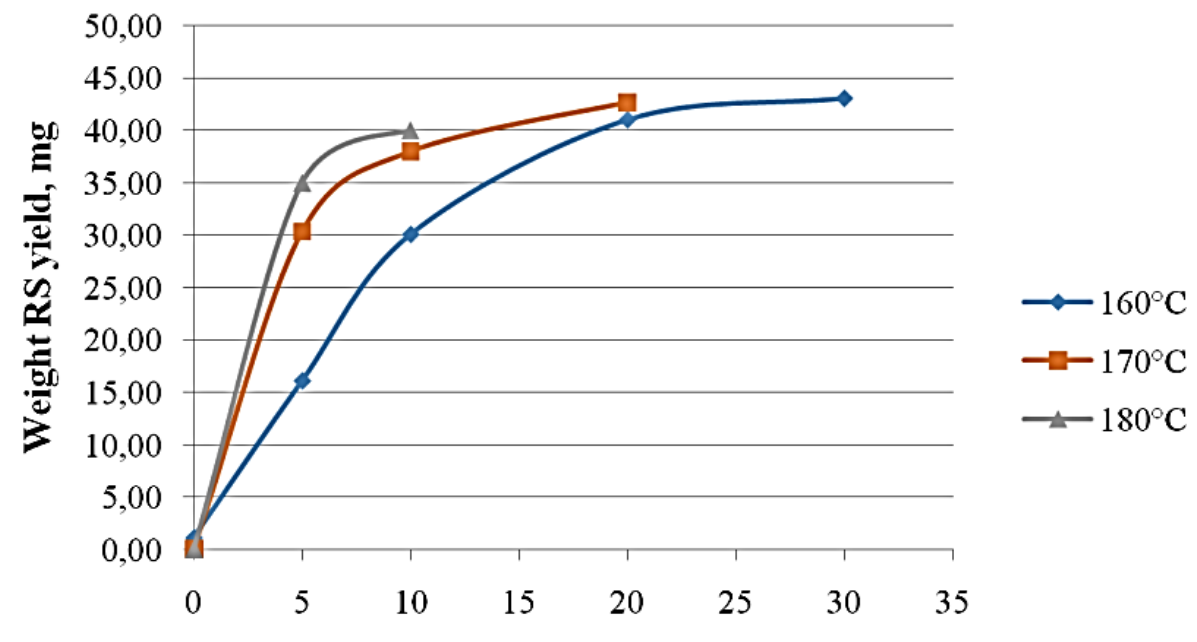

\section{Hydrolysis time, min}

Fig. 4. Reducing substances yield and pine sawdust hydrolysis duration relationship at $160^{\circ} \mathrm{C}, 170^{\circ} \mathrm{C}$ and $180^{\circ} \mathrm{C}$, sulfurous acid concentration of $4 \%$ at the first stage of hydrolysis.

The second stage of hydrolysis is carried out at the same temperatures, however, unlike the first stage, the duration of hydrolysis was increased (Fig. 5). According to the graph, it can be concluded that the duration of hydrolysis has less effect than the treatment temperature. 


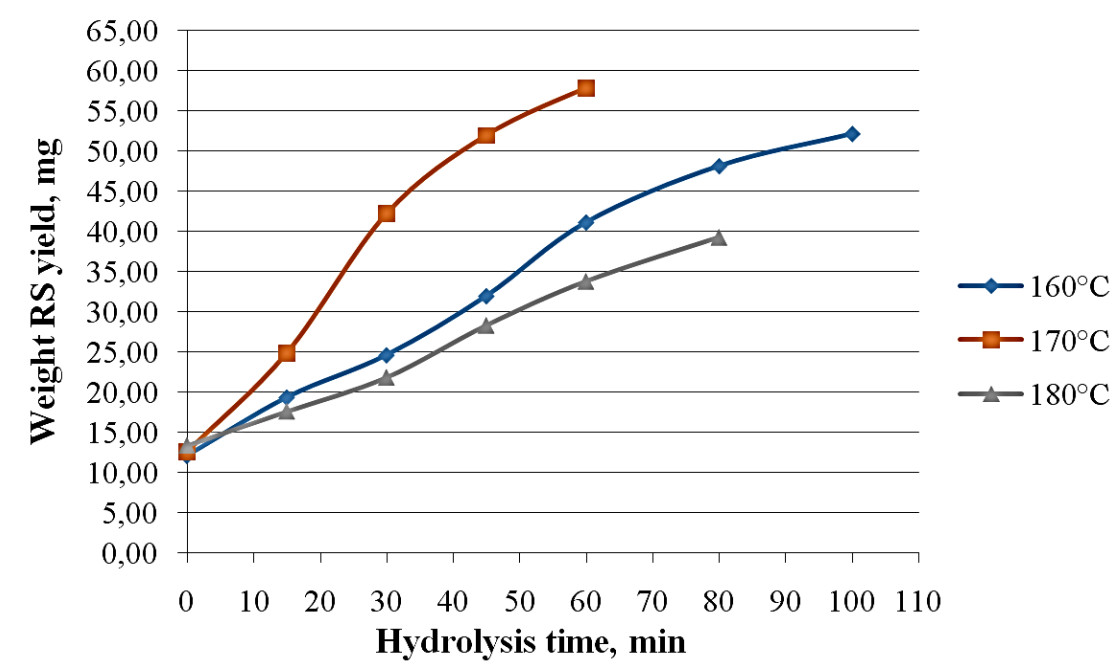

Fig. 5. Reducing substances yield and pine sawdust hydrolysis duration relationship at $160^{\circ} \mathrm{C}, 170^{\circ} \mathrm{C}$ and $180^{\circ} \mathrm{C}$, sulfurous acid concentration of $4 \%$ at the second stage of hydrolysis.

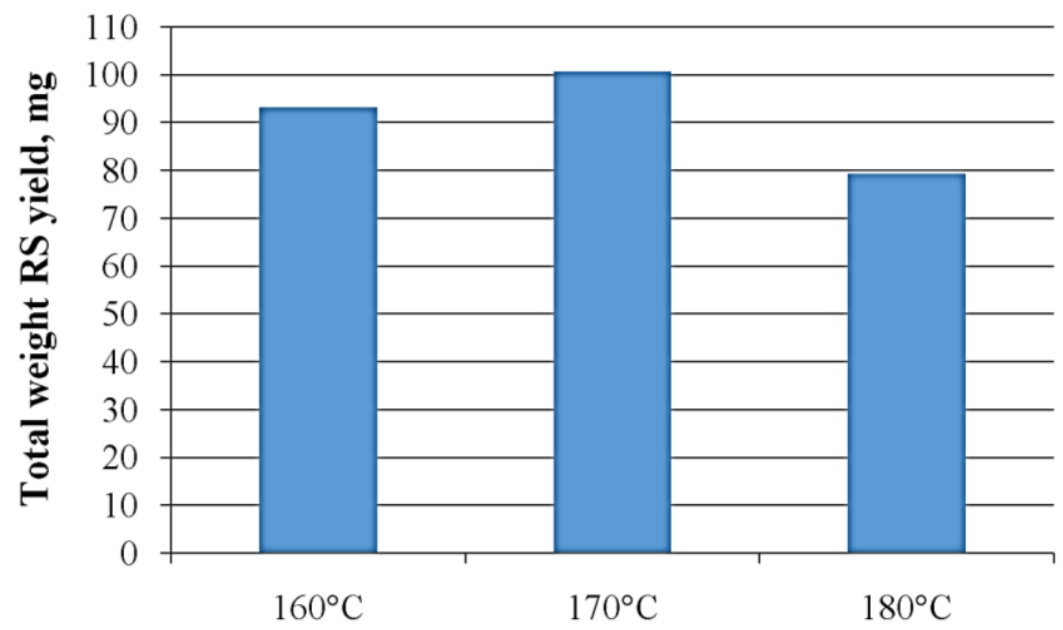

Fig. 6. Total RS mass yield depending on the hydrolysis temperature.

The analysis of the results of experimental studies of the effect of hydrolysis temperature on the total yield of aspen reducing substances showed that the optimal process mode was the temperature of $170^{\circ} \mathrm{C}$ (Fig. 6), which provides the highest yield of sugars after the 1 st and 2 nd stages of hydrolysis.

\section{Conclusion}

Our research on pine sawdust hydrolysis $160^{\circ} \mathrm{C}, 170^{\circ} \mathrm{C}, 180^{\circ} \mathrm{C}$ and sulfuric acid concentrations of $4 \%$ by weight showed that the highest yield of reducing substances in pine sawdust hydrolysates was provided at a temperature of $170^{\circ} \mathrm{C}$.

Based on the experiment data presented in Figures 3-5, it can be concluded that the periodic process of pine sawdust hydrolysis is advisable to be carried out in two-stages: at the first stage, after the release of easily hydrolyzed sugars, the latter should be drained and 
then sulfurous acid should be filled for the second stage of the process. This method of hydrolysis makes it possible to increase the total sugars yield to $6.5 \%$. The experiment allowed us to conclude that the two-stage mode of hydrolysis is reasonable since the release of sugars continues.

\section{Acknowledgment}

This work was supported by a grant from the President of the Russian Federation to support at the national level young Russian scientists who have a Ph.D. degree (MK-2246.2020.8).

\section{References}

1. C.M. Chan, L.-J. Vandi, S. Pratt, P. Halley, D. Richardson, A.Werker, B. Laycock, Composites of Wood and Biodegradable Thermoplastics: A Review, Polymer Reviews, 58(3), 444-494 (2018)

2. B. Adney, J. Baker, Measurement of Cellulase Activities, Chemical Analysis and Testing Task Laboratory Analytical Procedure. Golden: NREL, 11 (1997)

3. Rongfu Chen, Yoon Y. Lee, Robert Torge, Kinetic and modeling investigation on twostage reverse-flow reactor as applied to dilute-acid pretreatment of agricultural residues, Applied Biochemistry and Biotechnology, 57, 133- 147 (1996)

4. R.R. Safin, G.F. Ilalova, R.R. Khasanshin, Study of pyrolysis of annual crop refuse under reduced pressure, Solid State Phenomena, 299 SSP, 974-979 (2020)

5. T. Qiang, D. Yu, H. Gao, Y. Wang, Polylactide-Based Wood Plastic Composites Toughened with SBS, Polymer - Plastics Technology and Engineering, 51(2), 193-198 (2012)

6. S.R. Mukhametzyanov, R.R. Safin, G.F. Ilalova, A.R. Mukhtarova, A.I. Shageeva, Alternative energy in vegetable and crushed wood raw materials drying processes, IOP Conference Series: Earth and Environmental Science, 507(1), 012024 (2020)

7. N.R. Galyavetdinov, R.R. Safin, A.E. Voronin, Analysis of physico-mechanical properties of composites based on polylactide and thermally modified wood fibers, Materials Science Forum, 870, 202-206 (2016)

8. A.A. Fomin, V.G. Gusev, R.G. Safin, R.R. Safin, Dispersion of the margin removed in complex milling, Russian Engineering Research, 35(6), 417-420 (2015)

9. R.R. Safin, R.R. Khasanshin, A.R. Shaikhutdinova, R.R. Ziatdinov, The technology for creating of decorative plywood with low formaldehyde emission, IOP Conference Series: Materials Science and Engineering, 93(1), 012077 (2015)

10. R.R. Safin, R.R. Khasanshin, S.R.Mukhametzyanov, Influence of technical parameters of disk-shaped reactor on productivity of heat treatment of crushed wood, IOP Conference Series: Materials Science and Engineering, 327(4), 042095 (2018)

11. N.R. Galyavetdinov, R.R. Safin, A.E. Voronin, A.R. Shaikhutdinova, The mathematical modeling of the wood greenery extraction processes, Proceedings of 2015 International Conference on Mechanical Engineering, Automation and Control Systems, MEACS 2015, 7414885 (2016)

12. N.R. Galyavetdinov, R.R. Khasanshin, R.R. Safin, R.G. Safin, E.Y. Razumov, The usage of wood wastes in the manufacture of composite materials, International Multidisciplinary Scientific GeoConference Surveying Geology and Mining Ecology Management, SGEM 2015, 1(4), 779-786 (2015) 